\title{
Estado, pandemia e reprodução de desigualdades interseccionais no Brasil: uma reflexão a partir da tensão colonialidade/decolonialidade
}

\author{
State, pandemic and reproduction of intersectional \\ inequalities in Brazil: a reflection based on the \\ coloniality/decoloniality tension
}

\section{Estado, pandemia y reproducción de desigualdades interseccionales en Brasil: una reflexión basada en la tensión colonialidad/decolonialidad}

iD Bruno Ferreira Freire Andrade Lira

Universidade Federal da Paraíba, João Pessoa, Paraíba, Brasil

bffalira@gmail.com

Resumo: Desde 2015 o Brasil vem adotando com mais intensidade a retórica neoliberal do ajuste econômico e, consequentemente, alargando suas múltiplas formas de desigualdade social, agravadas com a chegada da pandemia. O objetivo do artigo é, portanto, refletir sobre como o pensamento decolonial pode contribuir na leitura sobre a esfera estatal brasileira na condução do enfrentamento da pandemia diante da reprodução do entrecruzamento de desigualdades - de classes, raciais e de gênero. A partir de uma revisão bibliográfica crítica, adota-se como chave analítica para o entendimento dessa realidade social a tensão colonialidade/decolonialidade. O tensionamento permite identificar que, se por um lado há uma racionalidade neoliberal que coloniza o Estado e a sociedade, por outro, resistem e existem - (r)existem - as Epistemologias do Sul e, mais especificamente, o pensamento decolonial, que tratam de visibilizar as experiências e as práticas de (r)existência das lutas sociais. A maior presença da esfera estatal brasileira é então requerida como forma de confrontar a intersecção de desigualdades, mesmo em um 
governo de forte cunho neoliberal. Nesse sentido, é preciso avançar na construção de uma agenda de reflexão e discussão acerca dos processos de reprodução das desigualdades interseccionais.

Palavras-chave: Decolonial. Estado. Desigualdades interseccionais. Neoliberalismo. Pandemia.

Abstract: Since 2015 Brazil has been adopting more intensely the neoliberal rhetoric of economic adjustment and, consequently, the country has been extending its multiple types of social inequality aggravated by the arrival of the pandemic. Therefore, this article aims to examine how decolonial thinking can contribute to reading the Brazilian state sphere in tackling the pandemic in face of the reproduced intersection of class, racial, and gender inequalities. Based on a critical bibliographic review, the coloniality/decoloniality tension has been adopted as an analytical key to analyzing this social reality. Tensioning allows us to identify that, if on the one hand, there is a neoliberal rationality that colonizes the State and society, on the other, the Epistemologies of the South resist and exist - (r)exist - along with, more specifically, decolonial thought, which do make the (r)existence experiences and practices of social struggles visible. A greater presence of the Brazilian state sphere is then required as a way of tackling the intersection of inequalities, even during a strongly neoliberal government. Thus, it is necessary to advance in building an agenda for reflection and discussion about the processes reproducing intersectional inequalities.

Keywords: Decolonial. State. Intersectional inequalities. Neoliberalism. Pandemic.

Resumen: Desde 2015 Brasil ha estado adoptando más intensamente la retórica neoliberal del ajuste económico y, en consecuencia, extendiendo sus múltiples formas de desigualdad social agravadas por la llegada de la pandemia. Por lo tanto, el objetivo del artículo es reflejar cómo el pensamiento decolonial puede contribuir a la lectura de la esfera del Estado brasileño en la conducción del enfrentamiento de la pandemia frente a la reproducción de la intersección de las desigualdades - de 
clases, raciales y de género. Sobre la base de una revisión bibliográfica crítica, se adopta la tensión colonialidad/descolonialidad como una clave analítica para entender esta realidad social. La tensión nos permite identificar que, si por un lado hay una racionalidad neoliberal que coloniza el Estado y la sociedad, por otro, resisten y existen - (r)existen - las Epistemologías del Sur y, más específicamente, el pensamiento decolonial, que tratan de hacer visible las experiencias y las prácticas de (r)existencia de las luchas sociales. La mayor presencia de la esfera del Estado brasileño es entonces requerida como una forma de confrontar la intersección de desigualdades, incluso durante un gobierno de fuerte naturaleza neoliberal. En este sentido, es necesario avanzar en la construcción de una agenda de reflexión y discusión sobre los procesos de reproducción de las desigualdades interseccionales.

Palabras clave: Decolonial. Estado. Desigualdades interseccionales. Neoliberalismo. Pandemia.

Data de recebimento: 20/10/2020

Data de aprovação: 18/02/2021 
Estado, pandemia e reprodução de desigualdades interseccionais no Brasil: uma reflexão... Bruno Ferreira Freire Andrade Lira

\section{Introdução}

O ano de 2020 no Brasil começou com uma sombra de incertezas, tanto pelos avanços de reformas com teor neoliberal, entre estas a da previdência aprovada em outubro de 2019, como pelo fortalecimento de discursos e pautas conservadoras ${ }^{1}$. Além disso, em um horizonte distante se pronunciava uma epidemia iniciada na China, denominada mais tarde de Covid-19, que se espalhava naquele país desde 2019 em uma velocidade jamais vista. É essa última penumbra que três meses depois haveria de tomar todo o planeta se transformando em uma pandemia com efeitos devastadores. Enquanto o mundo era tomado de assalto pela Covid-19 e as medidas de isolamento social ganhavam corpo como única alternativa efetiva para a diminuição da curva de contágio, o Brasil emergia com um discurso advindo da presidência da República de negacionismo quanto aos efeitos e as medidas para conter a pandemia.

Estabelece-se assim um cenário de disputas de narrativas no Brasil, uma baseada na ciência e em suas tentativas de descobrir mais informações sobre a Covid-19 assim como de uma vacina contra ela, e a outra centrada em negar a força da pandemia e os seus efeitos catastróficos. É mantendo o tom bélico e polarizado que o presidente Jair Bolsonaro (2019-atual) e seus "soldados" vêm conseguindo sustentar uma vida política. Todavia, o "jeito de governar" baseado na presença constante de um front trata de retirar os olhares da crescente situação de desigualdades e vulnerabilidade social brasileira. A reprodução destas já havia ganhado ares mais preocupantes a partir dos anos de 2014, como reflexo de uma crise econômica mundial iniciada em 2008 e um modelo desenvolvimentista brasileiro que demonstrava esgotamento ante a dependência do mercado mundial. É nos anos de 2016, com o impedimento de Dilma Rousseff (2011-16) e a chegada de Michel Temer (2016-18) à presidência da República,

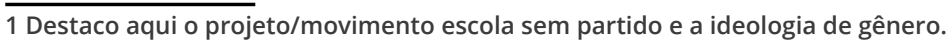


Estado, pandemia e reprodução de desigualdades interseccionais no Brasil: uma reflexão... Bruno Ferreira Freire Andrade Lira

que a pressão do mercado e da elite transnacional vai consolidar o retorno definitivo da retórica neoliberal e do ajuste fiscal.

Entretanto, as medidas associadas ao neoliberalismo no Brasil - como o teto de gastos, a reforma trabalhista, a reforma da previdência - acabam por acelerar o aprofundamento da desigualdade, eclodida com a situação de agravo provocada pela pandemia. Diante desse quadro de um crescente contexto de vulnerabilização social, proponho refletir sobre quais tessituras teórica-epistemológicas podem possibilitar uma compreensão ampliada acerca da relação entre o Estado brasileiro e a pandemia da Covid-19 ante a reprodução do entrecruzamento de múltiplas formas de desigualdade e classificação social no Brasil. O objetivo do texto é, portanto, refletir sobre como o pensamento decolonial pode contribuir na leitura sobre a esfera estatal brasileira na condução do enfretamento da pandemia ante a reprodução do entrecruzamento de desigualdades. Identifica-se aqui um cenário antagônico: um governo atual alinhado ao neoliberalismo que necessita fortalecer o papel do Estado em virtude da pandemia, como interventor na proteção social e do capital, mas sem perder o discurso de redução do próprio papel estatal.

O intuito do presente texto é construir elementos teóricoepistemológicos que auxiliem na elaboração de uma agenda de investigação acerca do papel do Estado frente ao entrecruzamento das múltiplas formas de desigualdade que têm se aprofundado com a pandemia. Para isso, o artigo será composto por quatro momentos: i) inicialmente, a partir de uma perspectiva global e do conhecimento crítico produzido no Norte, trato de refletir como tem sido construída a retórica neoliberal que tem aprofundado a reprodução das formas de desigualdades; ii) depois, proponho um diálogo entre as Epistemologias do Sul global e o pensamento decolonial latino-americano e caribenho, centrados nas lutas sociais contra as formas de opressão, apontando para outros horizontes; iii) estabelecido de forma crítica o pensamento hegemônico e, posteriormente, a proposta contra-hegemônica vinda do Sul global, analiso como o Estado brasileiro (2015-20) tem 
Estado, pandemia e reprodução de desigualdades interseccionais no Brasil: uma reflexão... Bruno Ferreira Freire Andrade Lira

agido no enfrentamento das desigualdades interseccionais, em especial no período pandêmico, a partir da tensão colonialidade/ decolonialidade; iv) concluo refletindo uma proposta de agenda voltada ao fortalecimento do debate sobre o entrecruzamento de desigualdades sociais no Brasil.

\section{0 neoliberalismo e a reprodução de desigualdades}

A compreensão do neoliberalismo, como a lógica recente do capitalismo, não se coloca como tarefa fácil, trazendo uma diversidade de interpretações. Aqui me situo, apoiado em leituras críticas, tanto a definir a prática neoliberal, como a sistematizar, sem exaurir, os períodos de sua expansão global e local.

Na primeira década do século XXI, o modelo desenvolvimentista adotado por diversos países latino-americanos e caribenho, com a liderança do Brasil e do "capitalismo de Estado" nomeado pela própria China, apresentou-se como alternativa à hegemonia estadunidense, mas não ao neoliberalismo. Este último não se encontra restrito a um Estado-nação ou uma comunidade política, mas, sim, exerce uma governança globalizada que prima por um utópico livre-mercado universalizado em que as pessoas supostamente estariam de forma constante competindo entre si e estabelecendo laços estritamente econômicos. Segundo Dardot e Laval (2016, p. 16), "o neoliberalismo pode ser definido como o conjunto de discursos, práticas e dispositivos que determinam um novo modo de governo dos homens segundo o princípio universal da concorrência". Para esses pensadores, a forma neoliberal de governar se exerce como uma atividade/técnica que rege condutas e comportamentos dentro das instituições - mercado, Estado, família, educação - a partir de uma racionalidade que prima pela concorrência constante e um modo gerencial de se viver.

Em outro trabalho, Harvey (2011, p. 27) vai apontar como o neoliberalismo se caracteriza como um "[...] projeto político de restabelecimento das condições da acumulação do capital e de 
Estado, pandemia e reprodução de desigualdades interseccionais no Brasil: uma reflexão... Bruno Ferreira Freire Andrade Lira

restauração do poder das elites econômicas". Aqui se identifica quem são os sujeitos a exercer esse novo modo de governo cujo intuito é a manutenção de uma estrutura social desigual em que o poder, ou seja, a capacidade de influenciar outros, permaneça concentrado com aqueles que detêm os meios de produção. Em ambas reflexões, aponta-se como a financeirização se torna a forma hegemônica do capital que domina as relações sociais cotidianas, a partir do suposto livre-mercado, subordinando o Estado e a sociedade à racionalidade neoliberal.

Apoiado em Harvey (2011), assim como em Dardot e Laval (2016), gostaria de dividir em três momentos, em termos sóciohistóricos, ${ }^{2}$ a expansão do neoliberalismo e o consequente fortalecimento de sua lógica mercadológica. O primeiro refere-se à construção teórica-epistemológica (1930-1960) feita, principalmente, por Friedrich Hayek (2017), Von Mises (2020) e Milton Friedman (1985), autores que estaleceram como principais adversários a regulamentação estatal e o coletivismo do Keynesianismo e do Estado de bem-estar social, estes como uma desvirtuação do liberalismo e uma aproximação perigosa ao comunismo. Assim, a teoria neoliberal se firma como um projeto político oposicionista à Social-democracia, propondo-se a renovar de forma crítica as bases do laissez-faire, corrigindo o que é considerado como elementos frágeis. Destaca-se aqui a ideia de que direitos como liberdade individual e propriedade privada não são leis naturais intangíveis, mas sim construídos e adquiridos dentro do sistema social, especialmente a partir das relações econômicas estabelecidas no livre-mercado. Outro ponto é referente à política e ao Estado, ou melhor, ao modo de governar, entendido agora como ferramenta essencial para garantir o pleno funcionamento do âmbito privado e o ordenamento jurídico.

Posteriormente, teve-se a consolidação do mercado global e do Estado gerencial (1970-1990) sob a hegemonia estadunidense, estabelecida na primeira experiência da ditadura civil-militar chilena do general Augusto Pinochet (1973-1990), e em sequência,

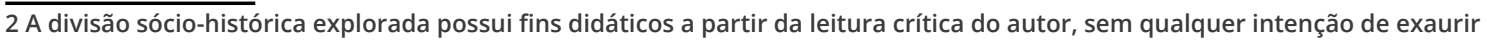
a discussão. 
Estado, pandemia e reprodução de desigualdades interseccionais no Brasil: uma reflexão... Bruno Ferreira Freire Andrade Lira

nos governos de Ronald Reagan (1981-1989) nos Estados Unidos e Margaret Thatcher (1979-1990) na Inglaterra. Destaque também para o Consenso de Washington (BRESSER-PEREIRA, 2003) que estabeleceu as diretrizes político-econômicas do neoliberalismo e as implementou pelo globo através das agências multilaterais como Fundo Monetário Internacional (FMI), Banco Mundial e Organização Mundial do Comércio (OMC). Com isso, buscou-se fortalecer a financeirização e uma globalização econômica, as elites transnacionais expandiam sua concentração econômica e política influenciando as tomadas de decisões locais (HARVEY, 2011). Isso alterou a forma de atuação estatal, agora voltada para a criação de situações de concorrência e parceria com os interesses oligopolistas fundamentados no mercado. Verifica-se aqui uma mercadorização da instituição do Estado tornando a ação pública dentro da lógica privada de suposta eficiência e flexibilidade. O Estado torna-se uma unidade produtiva que deve garantir o respeito às normas jurídicas e as boas práticas econômicas. Segundo Dardot e Laval (2016, p. 343), “o mercado mundial é um vasto entrelaçamento movediço de coalizões entre entidades públicas e privadas". O Estado-empresa é orientado para o consumidor, visto que o consumo em massa se propõe a padronizar as vidas sociais ao reduzir laços sociais em econômicos, determinando uma lógica de mercado na vida íntima.

Mais recentemente, houve a intensificação da captura das subjetividades pelo neoliberalismo (2000-atual) através especialmente das mídias digitais e redes sociais (CASTELLS, 2015). Neste momento, as fronteiras espaço-temporais são completamente rompidas pelos aplicativos e plataformas digitais que globalizam a comunicação e a informação. Permite-se que o capitalismo se aproprie das subjetividades coletivas e propague a falsa concepção de que apenas nele é possível a permanência da liberdade individual. A imersão do sujeito em um reducionismo econômico é fortalecida pela justificação de que a principal ação humana é empreender. Gera-se aquilo que Foucault (2008) chama de governo de si, em que o indivíduo é disciplinado pela racionalidade (neo)liberal baseada no cálculo, na previsibilidade e na maximi- 
Estado, pandemia e reprodução de desigualdades interseccionais no Brasil: uma reflexão... Bruno Ferreira Freire Andrade Lira

zação do bem-estar necessária para poder competir (BOURDIEU, 2005). O sujeito empreendedor buscaria agir de forma racional se arriscando nas oportunidades que se apresentam no intuito de vencer a competição, estimulada pelo mercado, e o consequente merecimento de uma vida social qualificada. Por isso se verifica o aumento da precarização do trabalho e o enfraquecimento dos sindicatos, visto que essa flexibilização permite que as empresas deixem de assumir os "riscos" da proteção social, que são transferidos para a responsabilidade dos assalariados - como exemplo, os vendedores classificados como colaboradores sob o regime do contrato temporário (BRAGA, 2012).

É nessa fase atual que se aprofunda a leviana ideia do sujeito enquanto capital humano, o qual deve crescer infinitamente (DARDOT; LAVAL, 2016). E para isso, dentro do pensamento neoliberal, o indivíduo precisa arcar com riscos, ganhar ou perder, que supostamente só é minimizado com a apreensão de conhecimentos e informações. Porém, a vida especulativa, tão cara ao capitalismo financeiro e neoliberal, apresenta-se como elemento central da geração de crises e do aprofundamento das desigualdades. O neoliberalismo desconsidera por completo as condições materiais/estruturais a que cada sujeito está inserido, assim como as relações de poder e conflito que cercam os laços sociais, estes erroneamente reduzidos ao econômico.

O neoliberalismo, assim, trata de naturalizar as formas de desigualdades apontando-as como gerativas da concorrência do mercado e da vida social - vistas somente de forma econômica. Omite-se que o capitalismo se caracteriza por ser um sistema altamente hierarquizado de variadas matrizes de dominação classe, racial, gênero. Ao não identificar o peso que a concentração de poder exige, pauta-se uma sociedade neoliberal ilusória, que esconde os abismos desiguais ao empurrar para o indivíduo a culpa da sua própria inferiorização.

\section{As experiências desde o Sul}


Estado, pandemia e reprodução de desigualdades interseccionais no Brasil: uma reflexão... Bruno Ferreira Freire Andrade Lira

Estabelecidos os elementos prático-teóricos que constroem a sociedade neoliberal, desde o Estado-empresa até a apreensão das subjetividades pela racionalidade concorrencial, é urgente explorar outras formas de compreensão da vida social. Assim, identifico as Epistemologias do Sul, cujo arcabouço teórico tem como principal expoente Boaventura de Sousa Santos, em Santos (2008; 2019) e em Santos e Meneses (2010). Primeiramente, não se trata de um Sul geográfico, mas sim um Sul global que é caracterizado por todos/as aqueles que se encontram em condições de opressão social, seja em nível global ou local. Os conhecimentos advindos dessa epistemologia, portanto, fundamentam-se nas experiências produzidas a partir das lutas sociais contra as formas de subordinação/inferiorização social. Aqui se localiza a ideia de resistir e existir - (r)existir -, enquanto o neoliberalismo busca recolonizar a vida social, os sujeitos oprimidos buscam meios de resistência que possibilitam viver mesmo diante de tantas formas de opressão racismo/pobreza/machismo/homofobia.

PorWallerstein (2007), pode-seidentificarqueas Epistemologias do Sul se constituem como tal a partir de um sistema-mundo moderno/capitalista/colonial/heteropatriarcal que tratou desde a sua formação de repartir o globo dentro da lógica de seres superiores e inferiores, inseridos primeiro entre metrópole e colônia, depois em centro e periferia. Assim, temos uma matriz de poder colonial que mantém relações de subalternização desde sempre. Nesse sentido, destaco um importante pensador martinicano, Frantz Fanon (2008), que identifica o colonialismo como um processo de constituição de um não-sujeito, o outro, a imagem inversa do colonizador homem/branco/europeu. Tem-se uma desumanização promovida pela destruição e/ou morte de saberes, vivências, práticas, um genocídio desde ontem até hoje - vide o Brasil, em que o maior número de homicídios é entre jovens negros, mesmo depois de mais de um século de fim da escravidão.

Aqui localizo o par privilégio/opressão, pois enquanto o(a) outro(a) permanece oprimido, há aqueles que continuam privilegiados usufruindo de uma estrutura social extremamente desigual 
Estado, pandemia e reprodução de desigualdades interseccionais no Brasil: uma reflexão... Bruno Ferreira Freire Andrade Lira

e concentradora. As Epistemologias do Sul buscam visibilizar os saberes produzidos por aqueles(as) que vivenciam as múltiplas formas de exploração/opressão/violência. No Brasil, isso é evidenciado pelas mulheres negras e pobres, pertencentes à franja de maior vulnerabilidade social que, apesar de se tornarem chefes de família, lidam com uma jornada dupla, renda precária e grau de escolaridade incompleto (BERNARDINO-COSTA, 2015). Apesar de tantas condições socioeconômicas adversas, essas sujeitas não deixam de lutar, criando filhos(as) para conseguirem romper com o ciclo de pobreza.

Diante dessa realidade social desigual, concordo com Santos (2008) que é preciso construir e fortalecer uma sociologia das ausências, ou seja, saberes e experiências que estão ausentes tornarem-se presentes e assim serem legitimados e valorizados ante o monologismo do conhecimento moderno ocidental. É preciso reconhecer a diversidade e pluralidade dos sujeitos e como as diferentes vivências produzem outros conhecimentos. A relação entre território, comunidades indígenas e natureza, por exemplo, é completamente distinta desta baseada na concepção monológica ocidental. A terra tem valor sagrado, pois propicia a vida através dos demais elementos do meio-ambiente que, por sua vez, é tratado com respeito e cuidado. Vê-se assim uma relação de afeto entre indivíduo e natureza, conectados na constituição da vida (WALSH, 2007).

O reconhecimento de si e das diferenças do outro - não mais como não-sujeito - é essencial para que esses saberes e experiências decorrentes das lutas sociais contra a opressão capitalista sejam transformados em práticas políticas, através de uma sociologia das emergências. Em outras palavras, emergir as vivências, conhecimentos e sujeitos tornando estas ações políticas que buscam alterar as condições de subalternização e inferiorização que está circunscrita o mundo. No Brasil, posso citar as marchas e protestos que são realizadas quando indivíduos negros são assassinados nas comunidades pobres das grandes cidades. 
Estado, pandemia e reprodução de desigualdades interseccionais no Brasil: uma reflexão... Bruno Ferreira Freire Andrade Lira

Nesse sentido, o conhecimento produzido no Norte global, aqui presente na reflexão crítica e desconstrucionista sobre o neoliberalismo, permanece importante, mas não deve estar acima daquele produzido no Sul. Estimula-se o diálogo plural e horizontal entre estes que possibilita fortalecer a crítica à doutrina neoliberal e financeira. As Epistemologias do Sul se caracterizam, assim, por uma ecologia de saberes extremamente plural e rica que apresenta diferentes pensamentos importantes. Assim, localizo a emergência do pensamento decolonial latino-americano e caribenho surgido nos anos de 1990 a partir do grupo Modernidade/Colonialidade (M/C) (ESCOBAR, 2003). O grupo M/C é formado por diferentes autores/as, cujas formações de pensamento são bastante diversas, passando pela dependentismo marxista, teologia da libertação, pós-estruturalismo, os estudos subalternos e culturais, feminismo e relações étnico-raciais (BALLESTRIN, 2013). Isso reflete a principal caraterística dessa rede de pensadores/as, a pluralidade epistêmica, fato que coaduna com a realidade da região latinoamericana e caribenha, extremamente plural e diversa em seus processos de subjetivação. Atualmente, o grupo $\mathrm{M} / \mathrm{C}$ se encontra como uma rede interdisciplinar de investigação espraiada pela América Latina e Caribe (CASTRO-GOMEZ; GROSFOGUEL, 2007).

Quijano (2000) traz então a concepção de colonialidade do poder que emerge identificando a incompletude do processo de descolonização. O pensador peruano ainda vai destacar que a colonialidade, como a racialização e o patriarcalismo, centrados na dicotomia superioridade/inferioridade, mantêm formas de classificação social que vão além da questão de classe. O próprio discurso da modernidade está baseado nessa relação hierárquica, definindo a América Latina e o Caribe, por exemplo, como periféricos e subdesenvolvidos. A real independência-seja política, social, econômica, cultural, moral - dos países latino-americanos e caribenhos apenas é realizável com a descolonização completa, que só pode ser almejada pela quebra do padrão de poder colonial e do estado de colonialidade. 
Estado, pandemia e reprodução de desigualdades interseccionais no Brasil: uma reflexão... Bruno Ferreira Freire Andrade Lira

Dentro desse cenário moderno/colonial/capitalista/heteropatriarcal e de dominação estadunidense-europeia, os territórios latino-americano e caribenho concluíram seu processo de formação de Estado-nações sem deixar de se tornarem dependentes da relação centro-periferia. Nesse contexto, o universalismo e a generalização promovidas pelo nacionalismo inibem que as diferenças étnicas, raciais e de gênero sejam reconhecidas e as experiências singulares e particulares são alijadas, assim, da memória social. Nesse sentido, é importante destacar o colonialismo interno, interpretado por Casanova (2009) inicialmente para explicar a situação indígena no México. As relações de dominação e classificação social não se colocam apenas no âmbito internacional entre nações, mas são reproduzidas internamente de forma a manter as estruturas histórico-hierárquicas, contribuindo para a permanência de um capitalismo periférico, dependente e colonial. Através disso, constroem-se identidades nacionais que invisibilizam as pluralidades dos distintos grupos sociais que dão forma à sociedade nacional.

Nessa perspectiva, concordo com Martins (2015), que a permanência das situações coloniais e a reprodução destas dentro dos territórios nacionais contribuem para o fortalecimento do enredamento de múltiplas hierarquias de classe/étnico-racial/gênero e, assim, discrimina em sujeitos superiores e inferiores, fornecendo privilégios a uns em detrimento de outros. Aqui, o que era identificado apenas como uma relação global, de superioridade/inferioridade entre nações, verifica-se também ao nível local, preservando e alargando os processos de marginalização e desigualdade social.

A pluralidade e as diferenças tão marcantes dos diversos povos da América Latina e Caribe foram subalternizadas pelo padrão de poder colonial, gerando um enredamento de nós histórico-estruturais heterogêneos (GROSFOGUEL, 2010; MIGNOLO, 2017). Estas formas se baseiam numa relação de superioridade e inferioridade entre os indivíduos e os grupos sociais. O padrão superior está circunscrito na figura do homem/branco/europeu-estadunidense/ cristão/heterossexual/militar que mantém situações coloniais, mais especificamente, hierarquizações de classe/étnico-racial/ 
Estado, pandemia e reprodução de desigualdades interseccionais no Brasil: uma reflexão... Bruno Ferreira Freire Andrade Lira

gênero/sexualidade, promovendo o enraizamento destas e a naturalização dessas formas. A colonialidade, nesse contexto, possibilita que alguns sejam identificados como superiores a outros, legitimando o poder através de relações de dominação. Portanto, não é apenas uma distinção de riqueza ou status, há elementos culturais, sociais e morais, também, que mantêm a colonialidade. O padrão de poder colonial, então, gera múltiplas formas de classificação social, promovendo uma reprodução permanente do entrecruzamento das desigualdades.

A inferiorização, assim, é naturalizada e reproduzida, gerando tanto uma colonialidade do saber como do ser (MALDONADOTORRES, 2019). O sujeito não se reconhece em seus processos de subjetivação, nem nas suas identidades, apenas nos símbolos nacionais e no cientificismo produzido nos países desenvolvidos. $O$ padrão de poder colonial avança para além do debate econômico e classista, distorcendo as formas de reconhecimento e de produção de saberes. Diante de tantos elementos, há a necessidade de descolonizar o poder, o saber e o ser.

A decolonialidade, portanto, circunscreve-se como formas de pensamento marginais, localizadas em zonas escuras, que são escondidas pelo discurso hegemônico da modernidade ocidental (MIGNOLO, 2017). Nesta, temos uma pluralidade de experiências, nascidas do colonialismo, porém mantidas sob a colonialidade e o padrão de poder colonial. O universalismo, o monologismo e a temporalidade linear moderna/capitalista/colonial são questionados a partir desse processo de desconstrução epistêmica. Não somente, como também as vivências e as práticas diversas que possibilitam a configuração de outros imaginários e saberes. Pode-se definir esta como uma epistemologia da sociologia das ausências que trata de tornar presente os conhecimentos deslegitimados. Outro elemento é o giro decolonial (CASTRO-GOMEZ; GROSFOGUEL, 2007), que são movimentos de rompimento com a lógica moderna/capitalista/colonial/heteropatriarcal que trazem consigo alternativas baseadas no contexto local, em diálogo com o global e no reconhecimento da pluralidade societal. Mignolo 
Estado, pandemia e reprodução de desigualdades interseccionais no Brasil: uma reflexão... Bruno Ferreira Freire Andrade Lira

(2017) identifica, então, um pensamento fronteiriço cada vez mais presente, ou seja, respostas epistêmicas do subalterno às relações de dominação e classificação social impetradas pelo sistema-mundo moderno/capitalista/colonial. A voz silenciada do colonizado pelo colonizador trata de emergir como forma de (r)existência para romper o monologismo e a universalidade.

É nessas três concepções - decolonialidade, giro decolonial e pensamento fronteiriço - que se edifica a ideia de (r)existir e confrontar a recolonização da vida social pela racionalidade neoliberal. Aqui deve se destacar a importância das ações coletivas, sejam de movimentos sociais, grupos acadêmicos ou variadas mobilizações, como alternativas que se forjam na busca de outras perspectivas e realidades ante ao avanço do neoliberalismo.

\subsection{A tensão entre colonialidade/decolonialidade}

Estabelecidas as construções teóricas dos termos colonialidade e decolonialidade, tem-se a constituição do pensamento decoIonial, mas como operacionalizar os diversos conceitos? Para isso, busca-se construir uma chave de leitura baseada no par privilégio/ opressão que é a constante tensão entre colonialidade/decolonialidade. O tensionamento trata de demonstrar que, apesar da colonialidade contida na hegemonia neoliberal e financeira, esta é confrontada por alternativas advindas do Sul, como é a decolonialidade pautada em práticas políticas de (r)existência ante a reprodução do entrecruzamento de desigualdades.

Retomando os termos centrais do pensamento decolonial, refletidos há pouco, posso situar a colonialidade em três níveis: i) a colonialidade do poder, demonstrada por Quijano (2010), em que as relações sociais, sejam no âmbito econômico, político, institucional, vigoram de forma hierárquica, excludente e opressora, gerando privilégios a uns e formas de subalternidades a outros; ii) e a colonialidade do ser, exemplificado pela homogeneização do pertencimento nacional, sendo aquele que age no campo das subjetividades e dos afetos, discriminando a pluralidade existente nas 
Estado, pandemia e reprodução de desigualdades interseccionais no Brasil: uma reflexão... Bruno Ferreira Freire Andrade Lira

sociedades e desconstruindo as coletividades; e iii) a colonialidade do saber, exercida pela geopolítica do conhecimento que legitima apenas o conhecimento moderno estadunidense-europeu, não reconhecendo outros saberes e práticas.

Acrescenta-se, ainda, o padrão de poder colonial (QUIJANO, 2010) que estrutura e sustenta o enredamento de diferentes formas de dominação e classificação social da colonialidade. Esse padrão se circunscreve atualmente na racionalidade neoliberal, apresentada na seção anterior deste artigo. O neoliberalismo e a financeirização, ao se pautarem na ilusão de que as relações econômicas são baseadas na pura racionalidade e previsibilidade, tratam de naturalizar uma colonialidade de poder que mantém o par privilégio/opressão. Além disso, a colonialidade do saber, ao imprimir o monologismo economicista, a colonialidade do ser e a naturalização das múltiplas formas de desigualdade, aprofundam as formas de dominação social inferiorizando e subalternizando grupos sociais.

A decolonialidade, por outro lado, impressa pelo giro decoIonial, possibilita desnaturalizar o entrecruzamento das desigualdades de classe, raciais, de gênero e sexualidade a partir da desconstrução das formas de colonialidade e da retórica econômica ortodoxa. Contudo, como podemos esmiuçar a decolonialidade? É importante, da mesma forma que identifico na colonialidade uma tríade, a verificação dos componentes alicerçadores do decolonial (MALDONADO-TORRES, 2019). Três conceitos são centrais:

i) a desmercadorização, tomada de Esping-Andersen (1991) e ressignificada pela decolonialidade, trata do grau de independência e autonomia do sujeito coletivo em relação ao livre-mercado ortodoxo. Enquanto a colonialidade do poder gera privilégios a uns em detrimento de tantos outros, desmercadorizar possibilita que estes outros, em sua coletividade, sejam reconhecidos enquanto sujeitos de direitos, capazes de questionar o padrão de poder colonial e aqueles grupos que a dominam. Aqui, concordo com Maldonado-Torres (2019), que identifica a possibilidade de um 
Estado, pandemia e reprodução de desigualdades interseccionais no Brasil: uma reflexão... Bruno Ferreira Freire Andrade Lira

ativismo social cotidiano pautado na formação de coletividades ou atitudes coletivas;

ii) a emancipação social (SANTOS, 2008) se refere à possibilidade do indivíduo de preservar suas subjetividades e formas criativas, buscando suas realizações pessoais inseridas nas demandas coletivas. Se a colonialidade do ser busca promover uma homogeneização invisibilizando as diferenças, emancipar pode permitir que esse sujeito se reconheça a partir de suas particularidades e afetos. A interculturalidade (WALSH, 2007) aponta como caminho para a promoção desse reconhecimento a diferença. Trata-se do processo de reconhecimento de si nas relações e experiências com os membros das nossas comunidades de pertencimento; e

iii) a pluralidade dialógica se refere à importância de reconhecer uma ecologia de saberes (SANTOS, 2008) e, paralelamente, estimular o diálogo horizontal entre o Sul e Norte. De forma antagônica, a colonialidade do saber, exercida por uma geopolítica do conhecimento, mantém o monologismo, a linearidade do tempo e o universalismo. O plural busca, então, a diversidade do conhecimento, a multiplicidade temporal e a associação entre o global e o local; todos os processos possibilitam a construção de pensamentos críticos fronteiriços. O dialógico (FREIRE, 1998) é o caminho para quebrar a retórica economicista que coloniza o cotidiano e possibilita o questionar e o pensar daquele que é colonizado.

As três formas da decolonialidade, antagônicas à colonialidade, apenas são possíveis através do giro decolonial, ou seja, movimentos de rompimento com a colonialidade e o padrão de poder colonial a partir de saberes, experiências e vivências múltiplas. Aqui é onde identifico uma sociologia das emergências em que as formas de (r)existência tornam-se práticas políticas de busca à igualdade de direitos e quebra do par privilégio/opressão.

Diante disso construo o Quadro 1, em que se localizam os elementos tanto da colonialidade como da decolonialidade, assim 
Estado, pandemia e reprodução de desigualdades interseccionais no Brasil: uma reflexão...

como os marcadores sociais correspondentes. Estes últimos são referências importantes que tratam de representar como a colonialidade e a decolonialidade se estabelecem na realidade social. Por exemplo, a manutenção da colonialidade do poder promove privilégios a poucos e, para confrontá-la, é necessário desmercadorizar a vida social, possibilitando o acesso a direitos coletivos de forma equânime.

Quadro 1 - A tensão colonialidade/decolonialidade

\begin{tabular}{|c|c|}
\hline $\begin{array}{c}\text { COLONIALIDADE } \\
\text { (marcadores) }\end{array}$ & $\begin{array}{c}\text { DECOLONIALIDADE } \\
\text { (marcadores) }\end{array}$ \\
\hline $\begin{array}{c}\text { Colonialidade do poder } \\
\text { (privilégios) }\end{array}$ & $\begin{array}{c}\text { Desmercadorização } \\
\text { (direitos) }\end{array}$ \\
\hline $\begin{array}{c}\text { Colonialidade do ser } \\
\text { (homogeneidade) }\end{array}$ & $\begin{array}{c}\text { Emancipação Social } \\
\text { (diferença) }\end{array}$ \\
\hline $\begin{array}{c}\text { Colonialidade do saber } \\
\text { (monologismo) }\end{array}$ & $\begin{array}{c}\text { Pluralidade dialógica } \\
\text { (diversidade) }\end{array}$ \\
\hline PADRÃO DE PODER COLONIAL & GIRO DECOLONIAL \\
\hline
\end{tabular}

Fonte: Elaboração própria.

A tensão colonialidade/decolonialidade, estabelecida a pormenorização dos seus elementos, é destacada neste texto como chave analítica fundamental para a compreensão do par privilégio/ opressão. É no interior desse tensionamento que se desenvolve a vida social, o indivíduo e os sujeitos coletivos. As experiências e vivências cotidianas estão circunscritas tanto por composições de manutenção da colonialidade e da reprodução de desigualdades como por práticas de (r)existências. As comunidades pobres nas grandes cidades brasileiras, em contexto de Covid-19, situam-se entre a necessidade de exposição ao trabalhar para não perder o emprego e a renda, imposta pela racionalidade neoliberal, e como criar alternativas que lhe deem seguranças sanitárias mínimas. Não exprimo, neste texto, uma vida social dicotômica, mas conflituosa, em que se intenta, a todo momento, a permanência de um controle 
Estado, pandemia e reprodução de desigualdades interseccionais no Brasil: uma reflexão... Bruno Ferreira Freire Andrade Lira

de condutas e comportamentos condizentes com a racionalidade neoliberal, gerando concentração de poder/renda/riqueza; porém, este é confrontado com formas de lutas sociais que exigem o reconhecimento das diferenças e a igualdade política.

\section{A pandemia e o Estado brasileiro}

Expostas tanto a racionalidade neoliberal como as Epistemologias do Sul, em especial o pensamento decolonial e, por conseguinte, a chave analítica da tensão colonialidade/decolonialidade, é possível agora analisar o contexto atual brasileiro verificando a relação entre a pandemia e a atuação do Estado acerca da reprodução do entrecruzamento de desigualdades sociais. É importante, antes, situar o imbricamento entre o capitalismo e a geração de crises. Em virtude do caráter desigual e contraditório, o sistema capitalista tende a gerar periódicas crises a fim de manter a desigualdade que é central na sua tessitura social. A consolidação do neoliberalismo e da dominação financeira, por exemplo, decorre de uma crise gestada durante a década de 1970, que provocou a recessão econômica em diferentes países, cuja solução apresentada foi promover ajustes fiscais, seja de desregulamentação da economia como de diminuição dos gastos sociais pelo Estado (SASSEN, 2016).

A racionalidade neoliberal, ao defender um suposto livremercado e reduzir as relações sociais a vínculos estritamente econômicos, passa a conceber os riscos como um fator inerente das boas práticas econômicas (DARDOT; LAVAL, 2016). Em sua lógica abstrata, as informações e os conhecimentos que permitem gerar cálculos e matrizes de previsibilidade são suficientes para minimizar os riscos e tomar as melhores decisões (BECK, 2011). A retórica ortodoxa, então, vende a justificação para naturalizar perdas e ganhos dentro da vida social concorrencial, mas omite as consequências não econômicas disso - pobreza, desemprego, doenças, impactos ambientais, quebra de laços sociais e outras. As 
Estado, pandemia e reprodução de desigualdades interseccionais no Brasil: uma reflexão... Bruno Ferreira Freire Andrade Lira

político-econômico desenvolvimentista ${ }^{4}$. Em termos estritamente econômicos, segundo Carvalho (2020), as medidas neoliberais adotadas de forma mais incisiva pelos governos de Michel Temer (2016-2018) e Jair Bolsonaro (2019-atual) não atenuavam a crise e sim prolongavam o ciclo econômico de contração. Em Harvey (2011), o autor identifica um papel singular da lógica neoliberal: os ajustes fiscais viriam no sentido de promover proteção às elites, detentoras da concentração de renda/riquezas, de forma a preservar a estrutura social desigual existente. No Brasil, isso não foi diferente, visto que uma das plataformas de sustentação da agenda política bolsonarista está vinculada às medidas ultraliberais do Ministro da economia Paulo Guedes.

Durante a campanha, Guedes defendeu privatizar todas as estatais, se declarou contrário aos reajustes automáticos de salário mínimo e chegou a divulgar uma proposta tributária que unificaria as alíquotas de Imposto de Renda, beneficiando os mais ricos. Ao fim do primeiro turno, Bolsonaro era considerado o candidato do mercado e das elites financeiras do país (CARVALHO, 2020, p. 22).

Dessa forma, o que se viu nos últimos cinco anos (2015-2020) no Brasil foi um aumento gradativo das formas de desigualdade assim como a piora das condições sociais para aqueles que se encontram na base da pirâmide socioeconômica. Segundo Barbosa, Ferreira de Souza e Soares (2020), isso é evidenciado pela diminuição da renda média daqueles $50 \%$ mais pobres e pelo crescimento favorável aos grupos mais ricos. Os mesmos autores concluem:

O ano de 2015 de fato representou uma recessão generalizada. Contudo, logo no ano seguinte, a recuperação econômica já seguia a pleno vapor para os $5 \%$ mais ricos - e pouco a pouco,

\footnotetext{
4 O desenvolvimentismo recente brasileiro, especialmente entre o segundo governo Lula e o primeiro Dilma, alinhou crescimento econômico com inclusão social (precária). O Estado possuía um papel ativo, seja no investimento público para a geração de empregos, seja no fortalecimento de uma rede de proteção social a partir da formalização do trabalho e da valorização real do salário mínimo (CEPÊDA, 2012).
} 
Estado, pandemia e reprodução de desigualdades interseccionais no Brasil: uma reflexão...

de cima para baixo, foi se tornando mais abrangente. Em 2018, a recessão já havia ficado para trás para a metade mais rica. Mas na base, ainda havia crise (BARBOSA; FERREIRA DE SOUZA; SOARES, 2020).

Este, portanto, é o cenário que a pandemia da Covid-19 encontra no Brasil, da implementação de uma agenda neoliberal e sua racionalidade associada à manutenção da colonialidade e da reprodução do entrecruzamento das desigualdades sociais. Sobre este último aspecto, acerca da interseccionalidade das formas de desigualdade, o neoliberalismo e a financeirização da vida cotidiana no Brasil não contribuem apenas para o aumento da pobreza, pois esta é ocupada em sua maioria por sujeitas negras e mulheres, o que implica na expansão da dominação racial e de gênero. Gonzalez (2011) já chamava a atenção na década de 1980 para a permanência da colonialidade, em que mulheres negras continuavam a ocupar postos precários de trabalho e acesso restrito à educação. O par privilégio/opressão coloca-se como norteador da estrutura social brasileira, ontem e hoje. Em relação à pandemia, a reflexão de Carvalho (2020, p. 6) enfatiza uma importante relação:
Além da perda de renda e trabalho, a base da pirâmide social, que no Brasil tem uma nítida dimensão racial e de gênero, está mais sujeita à contaminação e a desenvolver casos mais graves da infecção por Covid-19. Isso porque o risco de contaminação é maior pelo número de pessoas que dividem o mesmo dormitório, pelo uso de transporte público, pela falta de saneamento básico e pela dificuldade de manter o isolamento sem reduzir sua renda para abaixo do nível mínimo de subsistência (CARVALHO, 2020, p. 6).

A chegada da pandemia, em 2020, encontra no Brasil um contexto de grave vulnerabilidade social que tem contribuído para um crescente número tanto de contaminação como de óbitos. É importante destacar aqui o número crescente de óbitos entre os 
Estado, pandemia e reprodução de desigualdades interseccionais no Brasil: uma reflexão...

sujeitos negros, como se evidencia em um estudo realizado pelo Núcleo de Operações e Inteligência em Saúde (NOIS) do Centro Técnico Científico da PUC-Rio (CTC/PUC-Rio), e publicado pela Revista Galileu, em que avaliou cerca de 30 mil casos considerados graves e disponibilizados pelo Ministério da Saúde:

Um estudo liderado por pesquisadores da PUC-Rio e divulgado no último dia 27 de maio evidencia ainda mais essas disparidades. Em termos de óbitos por Covid-19, pessoas sem escolaridade têm taxas três vezes maiores $(71,3 \%)$ em relação àqueles com nível superior (22,5\%). Combinando raça e índice de escolaridade, o cenário fica ainda mais desigual: pretos e partos sem escolaridade morrem quatro vezes mais pelo novo coronavírus do que brancos com nível superior (80,35\% contra 19,65\%). Considerando a mesma faixa de escolaridade, pretos e pardos apresentam proporção de óbitos 37\% maior, em média, do que brancos (MARASCIULO, 2020).

Tais dados ajudam a visibilizar a permanência de um racismo estrutural (ALMEIDA, 2019), que legitima a segregação e o genocídio de grupos a partir de estereótipos e preconceitos construídos dentro de um padrão de poder colonial. Isso se reafirma em outros dados do NOIS (2020):

Conforme os registros do Ministério da Saúde, quase dez mil se identificaram como brancos e quase nove mil como pretos e pardos. Apesar da proximidade dos números, ao avaliar os óbitos, as diferenças se evidenciam: quase $55 \%$ dos pretos e pardos faleceram enquanto que, entre os brancos, esse valor ficou em 38\% (NOIS, 2020).

Nessa situação de forte desigualdade, é importante destacar, também, a centralidade do gênero feminino nessa intersecção das desigualdades. Segundo Bianconi (2020), do site 'Gênero e Número', especializado em divulgar e debater dados referentes 
Estado, pandemia e reprodução de desigualdades interseccionais no Brasil: uma reflexão... Bruno Ferreira Freire Andrade Lira

à equidade de gênero, o programa Bolsa Família (PBF) em 2018 tinha $68 \%$ de mulheres negras entre seus beneficiários. Além disso, podemos também enfatizar o trabalho doméstico como um serviço precário ocupado pela parcela mais pobre da população e altamente desvalorizado socialmente (SALATA, 2016). Em números referentes ao ano de 2018, o emprego doméstico representava $14,6 \%$ das mulheres ocupadas, sendo o segundo maior grupamento ocupacional desta população. Isso retrata um contingente de 5,7 milhões de mulheres, correspondente a $92 \%$ do total desses trabalhadores. Mas o fato a ser destacado é que $63 \%$ dessas domésticas são negras (PINHEIRO et al., 2019).

O retrato social brasileiro anterior à pandemia já trazia consigo uma realidade altamente desigual dentro de um entrecruzamento de matrizes de dominação. Nesse sentido, é importante retomar os marcadores sociais elencados anteriormente no Quadro 1 para compreender o aprofundamento das desigualdades. A situação pandêmica reforça os privilégios, visto que apenas poucos podem ficar em quarentena em suas casas. O discurso nacionalista e homogeneizante é reforçado como saída para supostamente amenizar os problemas sociais crescentes. E o monologismo economicista é ecoado ao colocar um peso maior na necessidade de dar continuidade ao trabalho e à produção capitalista, independente do agravo sanitário e do número recorde de internações e mortes.

A autora francesa Vergès (2020) destaca, em especial à economia do cuidado no período pandêmico, como sujeitas racializadas encontram-se ocupando o chão do capitalismo e garantindo o pleno funcionamento deste. Seja limpando ou cuidando do indivíduo branco, os corpos dessas trabalhadoras são esgotados e silenciados, tanto na exposição ao vírus como na manutenção das condições trabalhistas precárias. Estas mulheres são garantidoras do confinamento para os confinados ao ocuparem o lugar da limpeza e do cuidado.

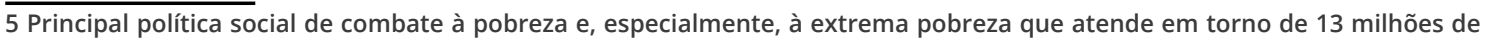
brasileiros/as. 
Estado, pandemia e reprodução de desigualdades interseccionais no Brasil: uma reflexão... Bruno Ferreira Freire Andrade Lira

Todavia, partindo do tensionamento colonialidade/decolonialidade, é preciso observar também as práticas de (r)existência que têm surgido ante aos avanços da racionalidade neoliberal e, de forma mais atual, da situação pandêmica. Se nos primeiros meses da pandemia no Brasil o governo bolsonarista tratou de adotar uma retórica negacionista, de necessidade de preservar a economia e rompantes de autoritarismo, de junho de 2020 para os dias atuais essa postura se modificou ante a piora das condições sociais, mas, especialmente, das (r)existências de diferentes grupos sociais que intensificaram a pressão por medidas anticíclicas - destaque para o conselho nacional de saúde (CNS), movimentos sociais e coletivos referentes ao gênero, à população negra e aos indígenas, sindicatos e associações trabalhistas ${ }^{6}$. Aqui é possível retomar os marcadores da decolonialidade em que se busca desmercadorizar em algum nível a vida social na busca de garantir direitos coletivos, garantindo acesso a um mínimo de bem-estar social; reconhecer as diferenças e necessidade específicas às populações indígenas e quilombolas, por exemplo, assim como comunidades pobres que necessitam de mais infraestruturas; e a capacidade de questionar e buscar o dialógico para a quebra de um economicismo que nega a vida e a saúde.

É importante destacar que a (r)existência possibilitou algumas poucas vitórias. Segundo Carvalho (2020), estaríamos na primeira fase de tomadas de decisão contra a pandemia, que se caracterizou pela implementação de uma renda emergencial básica para as camadas mais vulneráveis da população, fortalecimento da rede de proteção social, principalmente, o Sistema Único de Saúde (SUS), o seguro-desemprego e a remuneração de trabalhadores/as para a manutenção do vínculo empregatício; e o socorro financeiro às pequenas e micro empresas. Ressalto ainda que a adoção dessas medidas se coloca contrária à racionalidade neoliberal, pois 0 Estado passa a ter um papel muito mais ativo e interventor na economia. Inclusive, a justificativa para redução dos gastos estatais era o fato de este estar quebrado, não havendo liquidez para

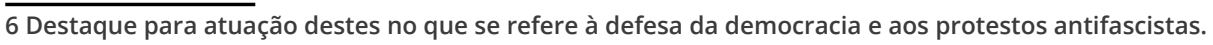


Estado, pandemia e reprodução de desigualdades interseccionais no Brasil: uma reflexão... Bruno Ferreira Freire Andrade Lira

propiciar investimentos públicos. Entretanto, diante das pressões que se colocaram, encontraram-se alternativas capazes de gerar fundos que revelam o mito da falência do Estado brasileiro, como demonstra Carvalho (2020):

Desse total, $R \$ 123,9$ bilhões referem-se ao pagamento de auxílio emergencial para pessoas em situação de vulnerabilidade, $R \$ 3$ bilhões à ampliação do programa Bolsa Família, R\$56,6 bilhões à concessão de parte do seguro-desemprego para trabalhadores com contrato de trabalho suspenso ou redução de jornada, $R \$$ 16 bilhões ao auxílio a estados e municípios, $\mathrm{R} \$ 34$ bilhões ao financiamento a empresas para pagamento da folha salarial e $\mathrm{R} \$ 23,96$ bilhões a despesas adicionais do Ministério da Saúde e demais ministérios (CARVALHO, 2020, p. 18-19).

A pandemia revela, assim, a importância de uma maior presença da esfera estatal na correção das desigualdades e das crises geradas pelo capitalismo. O Estado gerencial, como tem sido proposto pela racionalidade neoliberal, relega o indivíduo a sua própria sorte, apenas naturalizando e legitimando as múltiplas formas de desigualdades. Contudo, é importante ressaltar que o neoliberalismo e sua agenda de reformas não foram abandonados em plena permanência de crise, em especial no Brasil. Paralelamente ao papel mais ativo do Estado, retoma-se a apresentação de propostas de reformas tributárias e administrativas ${ }^{7}$, assim como a privatização de empresas estatais.

O Estado brasileiro encontra-se, então, em forte tensionamento entre colonialidade/decolonialidade, buscando atender os anseios do mercado global e das elites transnacionais e, em decorrência dos diferentes grupos de pressão, sendo também mais ativo no fortalecimento de uma rede de proteção social mínima ante a pandemia. Todavia, apesar de uma maior presença da esfera estatal, esta ainda parece ser insuficiente para o enfretamento das desigualdades interseccionais, ou seja, o entrecruzamento

7 As referidas reformas não se baseiam em propostas que atacam a forte desigualdade socioeconômica brasileira, mantendo os altos rendimentos sem taxações e/ou a desigualdade salarial no funcionalismo público. 
Estado, pandemia e reprodução de desigualdades interseccionais no Brasil: uma reflexão... Bruno Ferreira Freire Andrade Lira

entre os sistemas de dominação de classe, racial e de gênero. Isso decorre, principalmente, por essa agenda neoliberal estar sendo (re)implementada há cinco anos. Um exemplo é a (contra) reforma trabalhista brasileira de 2017, e suas posteriores ampliações, que tratou de aprofundar a precarização das relações trabalhistas, restringindo a capacidade de organização coletiva dos trabalhadores, assim como flexibilizando as formas de contrato e as jornadas de trabalho (LIMA; BRIDI, 2019). Isso intensificou a informalização no Brasil, aumentando o número de pessoas que não estão assistidas pela rede de proteção social do mercado de trabalho formal. A crise gerada pela pandemia precipita maiores consequências, o que assevera situações de pobreza - esta, no Brasil, de carácter interseccional.

Partindo da tensão colonialidade/decolonialidade, o agravamento socioeconômico associado à crise pandêmica da realidade brasileira urgiu por uma disputa ainda mais intensa pelo Estado, tomado nos últimos anos pela hegemonia da racionalidade neoliberal. A necessidade de apresentar alternativas para o agravamento da reprodução de desigualdades e do par privilégio/opressão ampliou o espaço para questionamentos mais contundentes acerca da manutenção da colonialidade.

\section{Considerações finais}

A reflexão proposta neste artigo buscou sistematizar alguns elementos que nos permitam construir ferramentas analíticas para a compreensão da realidade social que passamos a vivenciar no Brasil, em especial a de 2020, que é o aprofundamento das formas de reprodução da desigualdade social. Fernandes (2008) já identificava, na década de 1950, uma estrutura social brasileira extremamente desigual que associava um abismo entre classes e a manutenção de uma segregação racial. Saffioti (2015), também nos anos de 1950, reafirma essa ordem social hierárquica de classes, sendo esta articulada à permanência de uma divisão sexual binária 
Estado, pandemia e reprodução de desigualdades interseccionais no Brasil: uma reflexão... Bruno Ferreira Freire Andrade Lira

da vida social. Carneiro (2015), nos anos 2000, observa ainda a constância desse entrecruzamento de matrizes de dominação que subalterniza grupos sociais e estabelece uma massa de pessoas em situação de vulnerabilidade social.

Diante disso, posso afirmar que as crises geradas e gestadas pelo sistema-mundo capitalista/moderno/colonial/ heteropatriarcal, em especial no Brasil, são meios de manutenção da colonialidade, reproduzindo desigualdades interseccionais que se assentam no par privilégio/opressão. O agravamento do tecido social pela pandemia exige, primeiro, que continuemos a defender e estimular a realização das ações estatais de curto prazo, a qual possibilita condições mínimas de sobrevivência. Porém, é preciso também construir uma agenda de reflexão e discussão acerca de como enfrentaremos o agravamento do entrecruzamento das desigualdades sociais no Brasil. Nesse sentido, as Ciências Sociais têm um papel fundamental, desde construir ferramentas teóricometodológicas até a proposição de políticas públicas.

Em um momento de ininterruptas práticas de (r)existência, em que as formas de produzir saberes e conhecimentos vêm sendo descreditadas pela (ir)racionalidade neoliberal, é essencial que se permaneça na construção de entendimentos acerca da realidade social. O giro decolonial a ser promovido pelas Ciências Sociais brasileira centra-se na produção do artesanato intelectual, defendido por Mills (1982) e que se desdobra em cinco momentos: i) a valorização das experiências e vivências subalternas, tanto individuais como coletivas, que propiciam inquietações, questionamentos e saberes; ii) o armazenamento e o debate de ideias e fatos, a partir de leituras e discussões com diferentes sujeitos; iii) a construção de problemas de pesquisas, ou seja, que indagações são pertinentes para desvelar certo fato da realidade social; iv) a imaginação sociológica, trazendo a problemática vivenciada para o campo da teoria social e o arsenal de conceitos e pensamentos que esta possui; e v) o trabalho científico, a elaboração da reflexão propriamente dita, que atualmente vem se apropriando de forma mais intensa das tecnologias de informação 
Estado, pandemia e reprodução de desigualdades interseccionais no Brasil: uma reflexão... Bruno Ferreira Freire Andrade Lira

e comunicação (TICs), especialmente com a necessidade de uma permanência maior nos domicílios por conta da pandemia. Este último é ilustrado com o aumento da produção de podcasts, de ensaios científicos em outras plataformas além das revistas especializadas - aqui entra jornais, blogs -, de webinários que rompem com os limites do tempo e espaço.

Para o desenvolvimento de uma agenda que repense o Estado como meio de (r)existir à manutenção da ordem desigual, estabelecido o artesanato intelectual associado às TICs, deve-se ter como primeira estratégia a continuação e promoção da visibilidade das múltiplas formas de reprodução das desigualdades e da manutenção da colonialidade no Brasil, tendo a pandemia como contexto de análise. Torna-se importante e urgente evidenciar os mecanismos de fortalecimento, as experiências que são vivenciadas e as alternativas que têm se apresentado. Possibilita-se, assim, divulgar e expandir a produção científica em um contexto de forte negacionismo.

Outra estratégia é a construção/fortalecimento de espaços híbridos - tanto on-line como presenciais - voltados para o acompanhamento específico dos impactos da pandemia na reprodução de desigualdades interseccionais. A reflexão e o debate são fundamentais para se ampliar horizontes e entendimentos. A interdisciplinaridade, tão característica das Ciências Sociais, é primordial para agregar diálogos plurais que devem ir além do ambiente acadêmico. A presença de sujeitos dos mais variados setores da sociedade, articulando entre si ideias e projetos alternativos, é fundamental para a construção de políticas públicas.

O terceiro elemento é o engajamento e a ocupação de espaços que acessem o Estado. Se, por um lado, temos uma coalizão de governo que se pauta na racionalidade neoliberal e na manutenção da colonialidade, por outro, mantém-se uma democracia mínima que permite a participação popular e grupos de apoio dentro das instituições. A ativação da esfera estatal não é somente pelo voto, mas também pela ação política. As Ciências Sociais têm um papel fundamental, que é o estímulo do pensamento crítico a partir da 
Estado, pandemia e reprodução de desigualdades interseccionais no Brasil: uma reflexão... Bruno Ferreira Freire Andrade Lira

realização de pequenos encontros de ideias, webinários, fóruns com a apresentação de diferentes argumentos e relatos que aprofunde ainda mais as trocas de conhecimentos, propiciando uma ecologia de saberes.

A agenda dentro desse tensionamento entre colonialidade/ decolonialidade, ainda em construção, pode aparentar trazer consigo formas usuais de estratégias que dispomos nas Ciências Sociais. Entretanto, o artesanato intelectual, idealizado por Mills (1982), necessita incessantemente ser ressaltado, pois esta forma plural de pensar criticamente estabelece-se nos termos das vivências, leituras, análises e trocas, possibilitando a produção e disseminação de saberes. O momento de crise extrema que vivenciamos, eclodido com a pandemia que assevera o par privilégio/opressão, exige dos cientistas sociais olhares atentos às experiências vividas e como estas, a partir do aparato teóricometodológico, podem apontar alternativas e outras perspectivas.

\title{
30
}

\section{Referências}

\begin{abstract}
ALMEIDA, Silvio Luiz de. Racismo estrutural. São Paulo: Sueli Carneiro; Pólen, 2019.
\end{abstract}

BALLESTRIN, Luciana. América Latina e o giro decolonial. Rev.

Bras. Ciênc. Polít., Brasília, n. 11, p. 89-117, ago. 2013. Disponível em: http://www.scielo.br/scielo.php?script=sci_arttext\&pi$d=$ S0103-33522013000200004\&lng=en\&nrm=iso. Acesso em: 15 jun. 2020.

BARBOSA, Rogério; FERREIRA DE SOUZA, Pedro; SOARES, Serguei. Desigualdade de renda no Brasil de 2012 a 2019. Blog DADOS, 2020 [published 16 July 2020]. Disponível em: http://dados.iesp. uerj.br/desigualdade-brasil/. Acesso em: 31 jan. 2021

BECK, Ulrich. Sociedade de Risco: Rumo a uma outra modernidade. São Paulo: Editora 34, 2011. 
Estado, pandemia e reprodução de desigualdades interseccionais no Brasil: uma reflexão... Bruno Ferreira Freire Andrade Lira

BERNARDINO-COSTA, Joaze. Decolonialidade e interseccionalidade emancipadora: a organização política das trabalhadoras domésticas no Brasil. Soc. estado., Brasília, v. 30, n. 1, p. 147163, abr. 2015. Disponível em: http://www.scielo.br/scielo.php?script=sci_arttext\&pid=S0102=69922015000100147-\&Ing=en\&nrmiso. Acesso em: 15 jun. 2020.

BIANCONI, Giulliana. Maioria entre informais, mulheres têm lugar central na inédita renda emergencial. Gênero e Número, Rio de Janeiro, 27 de março de 2020. Disponível em: http://www.generonumero.media/mulheres-renda-emergencial/. Acesso em: 29 set. 2020.

BOURDIEU, Pierre. O campo econômico. Política \& Sociedade, Florianópolis-SC, n. 6, p. 15-58, abr. 2005. Disponível em: https:// periodicos.ufsc.br/index.php/politica/article/view/1930/1697. Acesso em: 15 jun. 2020.

BRAGA, Ruy. A política do precariado - do populismo à hegemonia lulista. São Paulo: Boitempo: USP, PPGS, 2012.

BRESSER-PEREIRA, Luiz Carlos. O Segundo Consenso de Washington e a Quase estagnação da Economia Brasileira. Rev. Econ. Polit., São Paulo, vol. 23, n 3 (91), p. 3-34, jul./set. 2003 Disponível em: http://www.rep.org.br/pdf/91-1.pdf. Acesso em: 15 jun. 2020.

CARNEIRO, Sueli. Racismo, sexismo e desigualdade no Brasil. São Paulo: Selo Negro edições, 2015.

CARVALHO, Laura. Curto-circuito: O vírus e a volta do Estado. São Paulo: Todavia, 2020.

CASANOVA, Pablo González. De la sociología del poder a la sociología de la explotación: pensar América Latina en el siglo XXI. Bogotá: Siglo del Hombre Editores y CLACSO, 2009.

CASTELLS, Manuel. 0 poder da comunicação. São Paulo e Rio de Janeiro: Paz \& Terra, 2015. 
Estado, pandemia e reprodução de desigualdades interseccionais no Brasil: uma reflexão... Bruno Ferreira Freire Andrade Lira

CASTRO-GÓMEZ, Santiago; e GROSFOGUEL, Ramon. Prólogo. Giro decolonial, teoría crítica y pensamiento heterárquico. In: CASTROGÓMEZ, Santiago \& GROSFOGUEL, Ramon. (coords.). El giro decolonial: reflexiones para una diversidad epistémica más allá del capitalismo global. Bogotá: Siglo del Hombre, 2007. p. 9-23.

CEPÊDA, Vera Alves. Inclusão, democracia e novo-desenvolvimentismo: um balanço histórico. Estudos Avançados, São Paulo, v. 26, n. 75, p. 77-90, ago. 2012. Disponível em: http://www.scielo.br/scielo.php?script=sci_arttext\&pi$d=$ S0103-40142012000200006\&lng=en\&nrm=iso. Acesso em: 15 jun. 2020.

DARDOT, Pierre; LAVAL, Christian. A nova razão do mundo: ensaio sobre a sociedade neoliberal. São Paulo: Boitempo, 2016.

ESCOBAR, Arthuro. Mundos y conocimientos de otro modo: el programa de investigación modernidad/colonialidad latinoamericano. Tabula Rasa, Bogotá, n. 1, p. 58-86, 2003.

ESPING-ANDERSEN, Gosta. As três economias políticas do welfare state. Lua Nova, São Paulo, n. 24, p. 85-116, set. 1991. Disponível em: http://www.scielo.br/scielo.php?script=sci_arttext\&pid=S0102-64451991000200006\&lng=en\&nrm=iso. Acesso em: 15 jun. 2020.

FANON, Frantz. Pele negra, Máscaras brancas. Salvador: Edufba, 2008

FERNANDES, Florestan. A integração do negro na sociedade de classes. Vol 1. 5. ed. São Paulo: Globo, 2008.

FOUCAULT, Michel. Nascimento da Biopolítica: curso dado no Collège de France (1978-1979). Tradução de Eduardo Brandão. São Paulo: Martins Fontes, 2008

FREIRE, Paulo. Pedagogia do Oprimido. 25 ed. (1ª edição: 1970). Rio de Janeiro: Paz e Terra, 1998.

FRIEDMAN, Milton. Capitalismo e liberdade. São Paulo: Nova Cultural, 1985. 
Estado, pandemia e reprodução de desigualdades interseccionais no Brasil: uma reflexão... Bruno Ferreira Freire Andrade Lira

GOHN, Maria da Glória. Novas teorias dos movimentos sociais. $4^{a}$ ed. São Paulo: Edições Loyola, 2012.

GONZALEZ, Lélia. Por um feminismo afrolatinoamericano.

Caderno de formação política Círculo Palmarino, n.1, 2011.

Disponível em: https://edisciplinas.usp.br/pluginfile.php/271077/ mod_resource/content/1/Por\%20um\%20feminismo\%20Afrolatino-americano.pdf. Acesso em: 16 jun. 2020.

GROSFOGUEL, Ramón. Para descolonizar os estudos de economia política e os estudos pós-coloniais: transmodernidade, pensamento de fronteira e colonialidade global. In: SANTOS, Boaventura de Sousa; MENESES, Maria Paula (org.). Epistemologias do Sul. São Paulo: Cortez, 2010, p. 455-491.

HAYEK, F. A. O caminho da servidão. LVM editora, 2017. HARVEY, David. O neoliberalismo: história e implicações. 2ª ed. São Paulo: Loyola, 2011.

LIMA, Jacob Carlos; BRIDI, Maria Aparecida. TRABALHO DIGITAL E EMPREGO: a reforma trabalhista e o aprofundamento da precariedade. Cad. CRH, Salvador, v. 32, n. 86, p. 325-42, ago. 2019. Disponível em: http://www.scielo.br/scielo.php?script=sci_arttext\&pid=S0103-49792019000200325\&lng=pt\&nrm=iso. Acessos em 30 set. 2020.

MALDONADO-TORRES, Nelson. Analítica da colonialidade e da decolonialidade: algumas dimensões básicas. In: BERNADINOCOSTA, J.; MALDONADO-TORRES, N.; GROSFOGUEL, R. Decolonialidade e pensamento afrodiaspórico. 2 ed. Belo Horizonte: Autêntica Editora, 2019. p. 27-53.

MARASCIULO, Marília. Na pandemia de COVID-19, negros morrem mais do que brancos, por quê? Revista Galileu, Rio de Janeiro, 29 de maio de 2020. Disponível em: https://revistagalileu. globo.com/Sociedade/noticia/2020/05/na-pandemia-de-covid-19- 
Estado, pandemia e reprodução de desigualdades interseccionais no Brasil: uma reflexão... Bruno Ferreira Freire Andrade Lira

negros-morrem-mais-do-que-brancos-por-que.html. Acesso em: 29 set. 2020.

MARTINS, Paulo Henrique. La actualidad de la tesis del coIonialismo interno. Apresentação de Trabalho/Comunicação. 2015.

MIGNOLO, Walter D. Colonialidade: o lado mais escuro da modernidade. Rev. bras. Ciências Soc., São Paulo, v. 32, n. 94, p. 1-18, jun. 2017. Disponível em: http://www.scielo.br/scielo. php?script=sci_arttext\&pid=S0102-69092017000200507\&lng=en\&nrm=iso. Acesso em: 16 jun. 2020.

MILLS, Charles Wright. A imaginação sociológica. $6^{a}$ ed. Rio de Janeiro: Zahar edições, 1982.

MISES, Ludwig Von. Ação humana: um tratado de economia. $2^{\text {a }}$ edição. Campinas, SP: Vide Editorial, 2020

NÚCLEO DE OPERAÇÕES E INTELIGÊNCIA EM SAÚDE (NOIS). Diferenças sociais confirmam que pretos e pardos morrem mais de COVID-19 do que brancos, segundo NT11 do NOIS. CTC/PUCRio, Rio de Janeiro, 27 de maio de 2020. Disponível em: http:// www.ctc.puc-rio.br/diferencas-sociais-confirmam-que-pretos-epardos-morrem-mais-de-covid-19-do-que-brancos-segundo-nt11do-nois/. Acesso em: 29 set. 2020.

PINHEIRO, Luana et al. Os desafios do passado no trabalho doméstico do século XXI: Reflexões para o caso brasileiro a partir dos dados da PNAD contínua. Texto para discussão (Instituto de Pesquisa Econômica Aplicada - IPEA). Brasília: Rio de Janeiro: IPEA, 2019.

QUIJANO, Aníbal. El fantasma del desarrollo en América Latina. Revista Venezolana de Economía y Ciencias Sociales, Caracas, vol. 6, n. 2, p. 73-90, 2000. Disponível em: https://red.pucp.edu. pe/ridei/wp-content/uploads/biblioteca/100520.pdf. Acesso em: 16 jun. 2020. 
Estado, pandemia e reprodução de desigualdades interseccionais no Brasil: uma reflexão... Bruno Ferreira Freire Andrade Lira

QUIJANO, Aníbal. Colonialidade do Poder e classificação social. In: SANTOS, Boaventura de Sousa; MENESES, Maria Paula (org.). Epistemologias do Sul. São Paulo: Cortez, 2010, p. 84-130. SAFFIOTI, Heleieth. Gênero, patriarcado, violência. $2^{\text {a }}$ ed. Expressão Popular, 2015.

SALATA, André Ricardo. Uma nova abordagem empírica para a hierarquia de status no Brasil. Rev. bras. Ciências Soc., São Paulo, v. 31, n. 92, p. 1-22, out. 2016. Disponível em http://www.scielo.br/scielo.php?script=sci_arttext\&pi$d=S 0102-69092016000300503 \&$ Ing=pt\&nrm=iso. Acesso em: 16 jun. 2020.

SANTOS, Boaventura de Sousa (org.). A gramática do tempo: para uma nova cultura política. $2^{\mathrm{a}}$ ed. São Paulo: Cortez, 2008. SANTOS, Boaventura de Sousa; MENESES, Maria Paula (org.). Epistemologias do Sul. São Paulo: Cortez, 2010.

SANTOS Boaventura de Sousa. 0 fim do império cognitivo: a afirmação das epistemologias do Sul. Portugal: Ed. Autêntica, 2019.

SASSEN, Saskia. Expulsões: brutalidade e complexidade na economia global. Rio de Janeiro/ São Paulo: Paz e terra, 2016.

WALLERSTEIN, Immanuel. Capitalismo histórico e civilização capitalista. Rio de Janeiro: Contraponto, 2007.

WALSH, Catherine. Interculturalidad y colonialidad del poder. Un pensamiento y posicionamiento "otro" desde la diferencia colonial. In: CASTRO-GÓMEZ, Santiago \& GROSFOGUEL, Ramon. (coords.). El giro decolonial: reflexiones para uma diversidad epistémica más allá del capitalismo global. Bogotá: Siglo del Hombre, 2007. p. 47-62.

VERGÈS, Françoise. Um feminismo decolonial. São Paulo: UBU editora, 2020. 